\title{
Marked Differences in the Signaling Requirements for Expression of CD203c and CD11b versus CD63 Expression and Histamine Release in Human Basophils
}

Donald MacGlashan, Jr.

Johns Hopkins Asthma and Allergy Center, Baltimore, Md., USA

\section{Key Words}

Activation markers $\cdot$ Histamine release $\cdot$ Desensitization $\cdot$ Actin polymerization

\begin{abstract}
Many techniques are being used to examine the status of circulating human basophils including the enhanced expression of a variety of cell surface proteins. There is accumulating evidence that there are at least two compartments containing these activation marker proteins but there are only some indications for the signaling requirements for each of the compartments. This study began with published reports by other investigators who potentially dissociated CD63 expression from anaphylactic degranulation with the p38 inhibitor, SB203580, a possible falsification of a previously proposed hypothesis regarding CD63 expression. To explore the signaling requirements for CD63, a variety of pharmacological agents were used to inhibit or enhance 4 endpoints of basophil activation. First, it was found that inhibition of both histamine release and CD63 expression with SB203580 was concordant. But it was also found that this agent had no effect on increased expression of CD203c and CD11b. Actin polymerization inhibitors caused marked enhancement of CD63 expression (concordant with their effects on degranulation) with no effect on expression of CD203C and CD11b.
\end{abstract}

The third generation syk inhibitor, NVP-QAB205, showed a 5-fold lower potency for inhibiting expression of CD203c and CD11b than for CD63. Finally, while desensitization of CD11b and CD203c expression occurs, it is slower than desensitization of the CD63 response. Taken together, these various observations demonstrate a marked difference in the early signaling requirements for the CD11b/CD203c compartment and CD63 degranulation and provide support for the hypothesis that CD11b and CD203c reside in a similar compartment.

Copyright $\odot 2012$ S. Karger AG, Basel

\section{Introduction}

Recent studies have begun to tease apart the conditions that lead to enhanced expression of various proteins that appear on the plasma membrane during different forms of stimulation of human basophils. Proteins such as CD63, CD203c and CD107a have been found to be useful replacement indicators of basophil activation and, with some caveats, markers of basophil histamine release [1-13]. However, various studies have noted that basophil responses measured by changes in surface proteins and mediator secretion are not always concordant $[4,5,7,14-$ 18]. If these surface markers of activation are to be used

\section{KARGER}

Fax +41 613061234 E-Mail karger@karger.ch www.karger.com (c) 2012 S. Karger AG, Basel

$1018-2438 / 12 / 1593-0243 \$ 38.00 / 0$

Accessible online at:

www.karger.com/iaa
Correspondence to: Donald MacGlashan, Jr.

Johns Hopkins Asthma and Allergy Center

5501 Hopkins Bayview Circle

Baltimore, MD 21224 (USA)

Tel. +1 410550 2145, E-Mail dmacglas@ jhmi.edu 
to understand the in vivo activation of basophils, then more information is needed about their signal transduction requirements to properly interpret what is occurring. For example, previous studies comparing changes in CD63 expression versus histamine release suggested that the two indicators of basophil activation could be dissociated under conditions where the type of degranulation was primarily of the so-called 'piece-meal' type [18-21]. Under these conditions, histamine release could occur without increased expression of CD63, but according to the model proposed, the reverse could not happen i.e. increased CD63 expression without histamine release. This is because additional CD63 only appears on the cell surface when histamine release occurs by anaphylactic degranulation.

This study developed from explorations into the signaling requirements for CD63 expression. There were two results that were discovered to further separate activation marker expression from histamine release. The first of these developed from three unrelated reports, that when taken together, suggested that CD63 expression could occur in the absence of histamine release, the precise condition that our proposed model predicted could not happen. A study by Gibbs et al. [16] demonstrated that the p38 inhibitor, SB203580, could inhibit histamine release. Inhibition in this study ranged from 60 to $70 \%$ for optimal levels of stimulation. In contrast, a study by Aerts et al. [5] indicated that SB203580 had little inhibitory effect on CD63 expression. In this study, optimal antigeninduced expression of CD63 was inhibited by only $11 \%$. In a study by Ebo et al. [22], optimal stimulation with anti-IgE antibody was inhibited by only $14 \%$. Taken together, the combined results might constitute a refutation of the proposed model of CD63 expression or at least strain the quality of the hypothesis. Therefore, this possibility needed to be examined in a side-by-side comparison of the inhibitor effects of this drug for histamine release and CD63 expression.

Since we were studying regulation of one activation marker, CD63, it was feasible to also study two additional markers from the same samples, CD203c and CD11b. There is developing information that CD203c expression is derived from a different compartment of the cell, although the precise nature of this compartment is not known. CD203c expression is clearly induced by substances that are not known to induce histamine release or CD63 expression [7, 17]. CD11b was included because there was suggestive evidence that the CD203c compartment might be a fast-release vesicle [4]. CD11b expression has been studied in some detail in neutrophils [23-27].
The protein is also expressed in basophils, being used by the basophil for the same purposes as the neutrophil [28]. Therefore, demonstrating similarity in the control of CD203c and CD11b would provide supportive evidence that CD203c was derived from the same compartment as CD11b and, therefore, immediately allow the base of knowledge about CD11b to be applied to CD203c.

The study expanded to several other pharmacological agents when unexpected results were found for regulation of CD203c/CD11b expression by SB203580. The actin polymerization inhibitors, latrunculin A or cytochalasins B or D have long been known to significantly upregulate mediator release [29-35]. One of the proposed mechanisms of this effect has been that actin polymerization modulates some of the early signal downregulatory events and, if so, it might be predicted that these drugs should act equally on events that resulted from early activation events. In addition, because CD203c expression appears to occur from a different compartment that might be a fast-release vesicle that is dependent on the actin network, it was useful to ask whether the effects of these actin polymerization inhibitors applied to this alternate compartment. The behavior of these agents was also unexpected and provided another example of the discordance of $\mathrm{CD} 203 \mathrm{c}$ expression from mediator release.

\section{Materials and Methods}

\section{Materials}

The following were purchased: piperazine-N,N-bis-2-ethanesulfonic acid (PIPES), bovine serum albumin (BSA), EGTA, ethylenediamine $\mathrm{N}, \mathrm{N}, \mathrm{N}^{\prime}, \mathrm{N}^{\prime}$ - tetraacetic acid (EDTA), D(+)glucose and fMLP (formyl-Met-Leu-Phe) - all from Sigma-Aldrich, St. Louis, Mo., USA, crystallized human serum albumin (HSA; Miles Laboratories, Elkhart, IN), SB203580 and latrunculin A (Calbiochem, EMD BioSciences, LaJolla, Calif., USA), cytochalasin D (Sigma), the 3rd-generation syk inhibitor, NVP-QAB205 (a gift from Glaxo-SmithKline), Percoll (Pharmacia, Piscataway, N.J., USA), anti-CD63 antibody (clone H5C6, BD BioSciences, San Jose, Calif., USA), anti-CD203c (clone NP4D6, BioLegend, San Diego, Calif., USA), anti-CD11b (clone Bear1, Beckman-Coulter, Sykesville, Md., USA) and mouse IgM anti-human IgE, HP6061P (Hybridoma Reagent Laboratory, Baltimore, Md., USA).

\section{Buffers}

PIPES-albumin-glucose (PAG) buffer consisted of $25 \mathrm{~mm}$ PIPES, $110 \mathrm{~mm} \mathrm{NaCl}, 5 \mathrm{mM} \mathrm{KCl}, 0.1 \%$ glucose and $0.003 \% \mathrm{HSA}$. PAGCM was PAG-supplemented with $1 \mathrm{mM} \mathrm{CaCl}_{2}$ and $1 \mathrm{mM}$ $\mathrm{MgCl}_{2}$. PAG-EDTA consisted of PAG supplemented with $4 \mathrm{mM}$ EDTA, elutration buffer and PAG containing $0.25 \%$ BSA. Phosphate-buffered saline (PBS) was $20 \mathrm{~mm}$ phosphate-buffered isotonic saline ( $\mathrm{pH} 7.4)$ and was often supplemented with $4 \%$ BSA (Sigma). 


\section{Basophil Purification}

While flow cytometry for CD63 or CD203 could have been performed with whole blood or mixed leukocytes, some of the experiments required purified basophils; to be consistent, all were performed with purified basophils. Residual cells of normal donors undergoing leukapheresis were enriched in basophils using a combination of Percoll density gradients and countercurrentflow elutriation and negative selection, as previously described [36]. Basophil purities generally exceeded 99\% purity. HIPPA (confidentiality and privacy) regulations do not allow identification or classification of the leukapheresis donors, so information regarding the atopic status of the subjects was not available.

\section{Basophil Stimulation for Activation Markers and Histamine} Release

When both activation markers and histamine release were assessed, purified basophils (600,000-800,000 per condition) were challenged in $60 \mu \mathrm{l}$ of PAGCM buffer for $20 \mathrm{~min}$ at $37^{\circ} \mathrm{C}$, after which $10 \mu \mathrm{l}$ of cell suspension was transferred to cold EDTA-PAG and centrifuged to pellet the cells and recover the supernatant for the measurement of histamine content. Histamine was measured in supernatants by automated fluorometry [37]. To stop the reaction, , $50 \mu \mathrm{l}$ of a $2 \%$ paraformaldehyde solution in PBS was added to the remaining cell suspension and incubated for $10 \mathrm{~min}$ at $37^{\circ} \mathrm{C}$ prior to adding $1.5 \mathrm{ml}$ of a solution of $4 \%$ BSA in PBS for storage at $4^{\circ} \mathrm{C}$ until the day of flow cytometry. If only flow cytometry was performed, the removal of cells for histamine release was excluded from the protocol. For drug testing, the reaction normally included a 10 -minute period of incubation with the drug at the specified concentrations prior to adding the stimulus. All drugs were dissolved in DMSO and the 'vehicle control' samples included DMSO at a concentration equal to that of the highest drug concentration being tested. Throughout the manuscript, the results are first calculated as a fraction of 'vehicle control response', meaning the response to stimulation in the presence of DMSO (see above). These fractional values are used for averaging.

For desensitization experiments, the reaction was carried out in 2 phases, a calcium-free phase ranging from 0 to $45 \mathrm{~min}$ followed by restoration of extracellular calcium to allow secretion for another $45 \mathrm{~min}$. For the first phase, the cells were resuspended in PAG buffer containing $50 \mu \mathrm{M}$ EDTA \pm anti-IgE antibody for different periods of time. The samples without anti-IgE were considered nondesensitized cells; they experienced the absence of extracellular calcium for the same periods as the stimulated cells. These conditions are included because depriving the cells of calcium for extended periods sometimes causes a small loss of responsiveness. After this 'desensitization' phase (calcium-free stimulation), the cell response was tested by the addition of extracellular calcium in the form of a PAG-CM buffer (containing appropriate concentrations of stimulus) and the secretion reaction allowed to proceed for an additional $45 \mathrm{~min}$ prior to the fixation of the cells for analysis of activation markers.

\section{Flow Cytometry}

Each sample of the stored suspension of fixed basophils was divided into 3, for labeling with either anti-CD63 (1/1,000 dilution from manufacturer's stock solution), anti-CD203c (1/500 dilution) or anti-CD11b (1/500 dilution). The primary metric of change in the flow cytometric studies was the difference in the means of flow cytometric distributions between unstimulated and stimulated cells. For CD63, the alternative method of assessing the response that is common in the literature, net percent positivity, was also analyzed, but there were minimal quantitative differences from the mean measurement and no qualitative differences. Since these studies were done with purified basophils, the only gating criterion was a forward-scatter/side-scatter gate to remove nonintact cells from the analysis.

\section{Statistics}

In general, data is shown as the mean \pm standard error of the mean, both in the text and figures. In some instances, the figure shows mean \pm SEM but because the data includes stimulation \pm drug, the appropriate statistical analysis uses a paired Student $t$ test i.e. the reported $p$ values are derived from paired analysis. For the dose-response curves shown in figure 1b, MANOVA statistics ( 2 conditions \pm drug vs. 3 outcomes) were calculated using the area-under-the-curve metric for the results. An approximate statistical power to detect change in the dose-response curve calculation determined that a $27 \%$ change could be detected with $80 \%$ power. For the comparison of SB203580-mediated inhibition of CD63 expression and histamine release, the data points were fitted to a line; the slope and intercept and their respective errors of estimation were determined. The standard linear regression was chosen under the assumption that histamine release is the gold standard which is possibly predicting CD63 expression. However, the assay could also be viewed as 2 exchangeable outcomes; in which case, a Passing-Bablok test is more appropriate and was thus performed in addition to the standard linear regression.

\section{Results}

As noted in the introduction, a previous study by Gibbs et al. [16] demonstrated that SB203580 inhibits histamine release, while Aerts et al. [5] reported that this drug did not inhibit CD63 expression. We examined a short-series dose-response curve, from 0.3 to $10 \mu \mathrm{M}$, and examined the expression of CD63, CD203c, CD11b ( $\mathrm{n}=$ 4) and histamine release (in 3 of the 4 experiments) in response to anti-IgE antibody. Our primary end point in this series of experiments was to determine if there was discordance in the inhibition of CD63 expression and histamine release. Figure 1a plots all the data (from any drug concentration) from the 3 matched experiments and demonstrates a tight concordance. It shows the expectation for perfect concordance (dotted line) and the linear fit where the y-intercept $(0.056 \pm 0.112)$ and slope $(0.846$ \pm 0.149 ) are not statistically different from 0 and 1.0 , respectively. A Passing-Bablok statistical test on this result had the same conclusion: slope $=1.05$, CI 0.75 to 1.35 and intercept $=-0.0005, \mathrm{CI}-0.23$ to 0.23 ). These experiments also revealed an unexpected result, the absence of the inhibition of CD203c and CD11b (fig. 1b; for CD203c and 


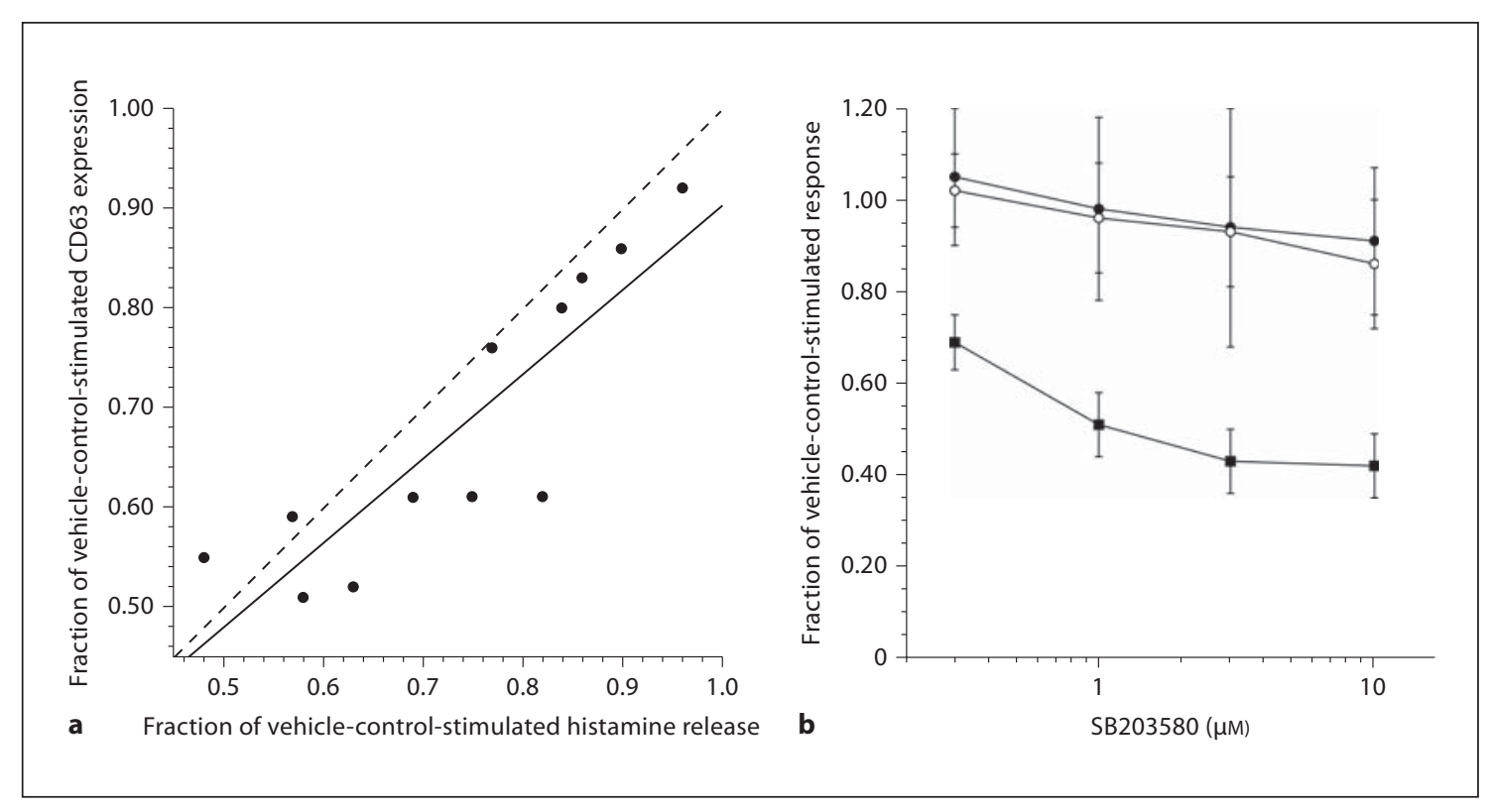

Fig. 1. Concordance of the inhibition of histamine release and upregulated CD63 expression by SB203580. a Using data from 3 experiments in which 4 concentrations of SB203580 were examined, a plot of the fractional response with histamine release versus CD63 expression as the outcome is shown. Dashed line: perfect concordance, solid line: the fit of the actual data. $\mathbf{b}$ In these experiments, purified basophils were stimulated with an optimal concentration of anti- $\operatorname{IgE}$ antibody $(0.5 \mu \mathrm{g} / \mathrm{ml})$ after a 10 -minute preincubation with SB203580 at the various concentrations shown in $\mathbf{b}$. The average stimulated response for these experiments was $82 \%$. b Concentration dependence of the inhibition by SB203580 of the anti-IgE antibody-induced response. $\mathbf{\square}=\mathrm{CD} 63$; $\mathrm{O}=\mathrm{CD} 203 \mathrm{c} ; \boldsymbol{- C D 1 1 b}$. Data is calculated relative to the vehicle control IgE-mediated response $(n=4)$.
CD11b, $\mathrm{p}>0.05$ and for CD63, $\mathrm{p}=0.0002$ for the difference from the control).

A variety of studies in both animal mast cell models and human basophils have shown that inhibition of actin polymerization by either latrunculin A or cytochalasin D markedly enhances histamine release [29-33]. Although one of the speculated mechanisms for this effect would predict that it should enhance CD63 and CD203c expression, there were other ways of viewing the effects of these drugs indicating a need to study these effects. Previous studies determined the concentration dependence of the drugs on the dissolution of polymerized actin in human basophils; a $2 \mu \mathrm{M}$ concentration of cytochalasin D or 200 nM latrunculin A optimally alters actin polymerization $[34,35]$. So cells were tested with these concentrations. Figure 2a shows that latrunculin A had no statistically significant effect on CD203c expression while markedly enhancing CD63 expression in response to anti-IgE antibody. The enhanced expression of CD63 was consistent with previous studies of enhanced histamine release and in 1 of the experiments, also concordant with the enhancement of histamine release. Similar results were ob- tained for cytochalasin D, with a 4.8-fold increase in IgEmediated CD63 expression. Previous studies have noted that actin polymerization inhibitors also enhance nonIgE-dependent secretagogues. A similar pattern of behavior was confirmed for CD63 and CD203c when using fMLP (100 nM) as a stimulus. With latrunculin A, CD203c expression was $1.03 \pm 0.19$-fold $\left(n=5, H_{0}=1 ; p=n\right.$.s. $)$ of the response with the vehicle control and with cytochalasin $\mathrm{D}, 1.03 \pm 0.28$-fold $(\mathrm{n}=4$; $\mathrm{p}=$ n.s.). In 3 experiments, the expression of CD63 was enhanced 1.5-, 5.1and 5.6-fold with latrunculin A (4.5-fold average). In 2 experiments with cytochalasin D, CD63 expression was enhanced 1.8- and 4.5-fold (3.2-fold average). Figure 2b shows that there was no difference in the kinetics of CD203c expression following fMLP $\pm 200 \mathrm{nM}$ latruncu$\operatorname{lin} \mathrm{A}$.

It has recently been shown by other experimental maneuvers that IgE-mediated desensitization does not appear to be influenced by actin polymerization, despite the fact that overall mediator release is enhanced [35]; however, studies in other cell types have suggested that actin polymerization should have influenced the downregula- 
Fig. 2. Effects of latrunculin A on CD63 or CD203c expression. a Purified basophils were incubated for $10 \mathrm{~min} \pm 200 \mathrm{nM}$ latrunculin A (or DMSO, vehicle control at a DMSO concentration equivalent to that in the latrunculin A condition) before stimulation with an optimal concentration of anti- $\operatorname{IgE}$ antibody $(0.5 \mu \mathrm{g} / \mathrm{ml})$. b Kinetics of fMLP-induced CD203c expression $\pm 200 \mathrm{nM}$ latrunculin A. $\bullet=$ Vehicle control; $\bigcirc=200$ nM latrunculin A $(n=3)$. To average the data from 3 experiments, all data within a particular experiment was expressed as a fraction of the vehicle-control response at $5 \mathrm{~min}$.

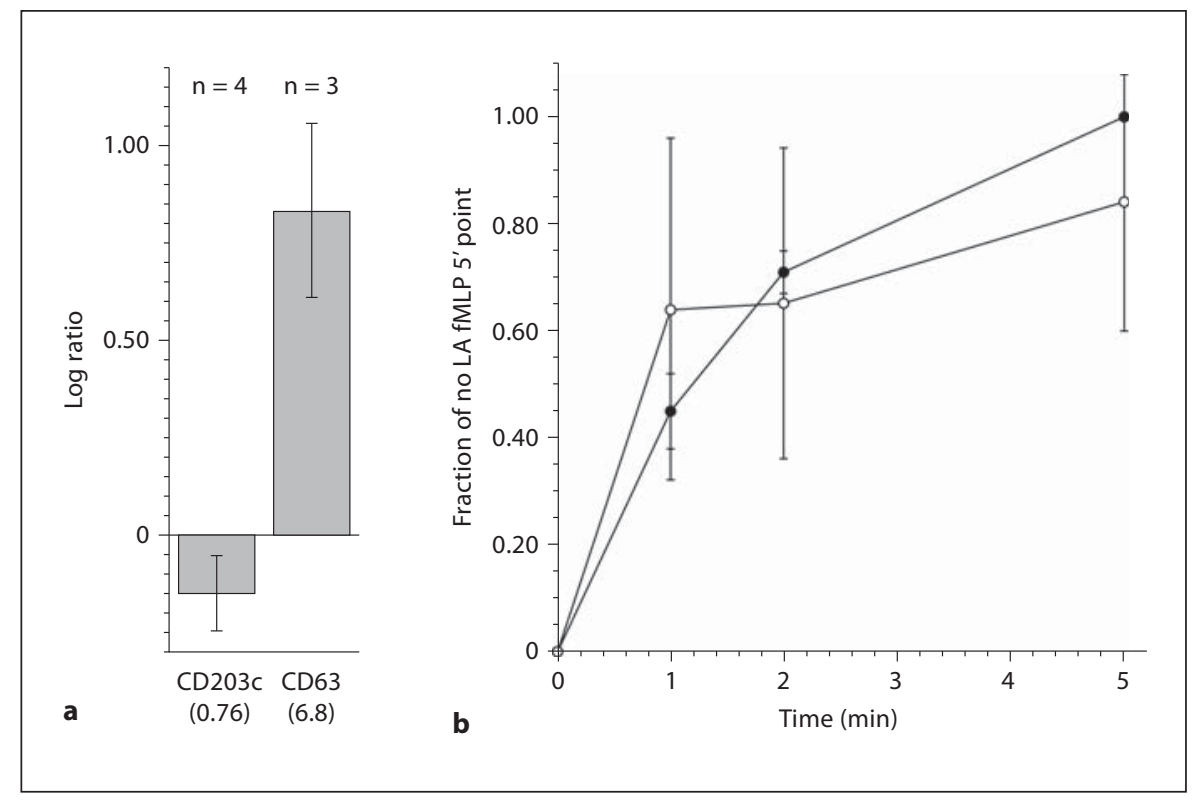

tion of the IgE-mediated response [38-40]. As noted above, it was found that latrunculin A, and by proxy, actin polymerization, had no effect on CD203c expression. If actin polymeriziation did, in fact, determine whether desensitization occurred, then the stimulated expression of CD203c might not show desensitization because expression occurred to the same extent regardless of the presence of actin inhibitors. A recent study by Lund et al. [41] demonstrated desensitization of CD203c expression using a sub-threshold method. The signaling requirements for this approach to demonstrating FceRImediated desensitization have not been explored; so to link results for CD203c with our previous signaling studies, FceRI-mediated desensitization was studied with the calcium-free method using anti-IgE antibody as the stimulus. The operational method of demonstrating the intrinsic self-termination mechanisms is to incubate cells in the absence of extracellular calcium with the stimulus for various periods of time, after which calcium is returned to the buffer (subsequent histamine release decays with time). This is a method with considerable history [see 42-46]. Figure 3 shows that desensitization of CD203c occurs. However, the rate is somewhat slower, and within this time frame the rate slows to the extent that it is difficult to detect at times greater than $30 \mathrm{~min}$. Note that CD63 expression desensitized rapidly, at a rate consistent with desensitization measured by histamine release and consistent with many prior studies of this phenomenon $[46,47]$. Once again, the behavior of CD11b during desen-

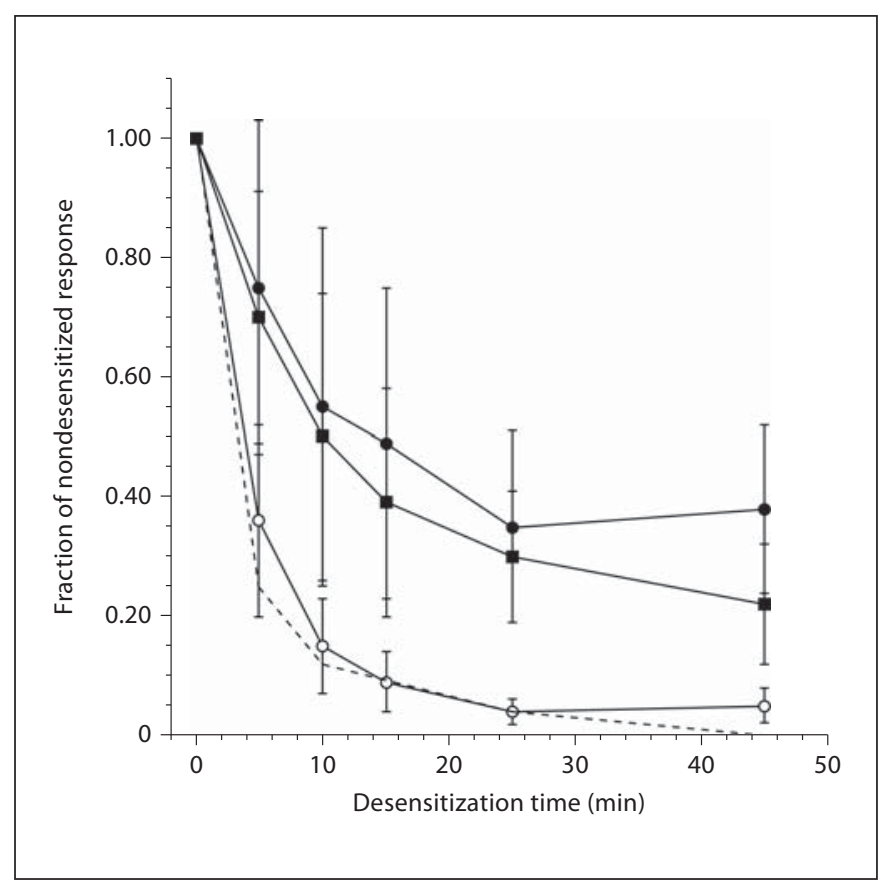

Fig. 3. Kinetics of IgE-mediated desensitization as measured by the expression of CD63 (O), CD203c (•) or CD11b ( $\boldsymbol{\square})(\mathrm{n}=3)$. Basophils were incubated with an optimal concentration of anti$\operatorname{IgE~Ab~}(0.5 \mu \mathrm{g} / \mathrm{ml})$ in the absence of extracellular calcium $(50 \mu \mathrm{M}$ EDTA) for the time periods shown on the abscissa, after which extracellular calcium was returned to the buffer and the cells were incubated for an additional $20 \mathrm{~min}$ before fixation. Dashed line: results from 1 experiment to verify that the rate of desensitization measured by histamine release in this study is consistent with past experience. 
Fig. 4. Inhibition of CD63, CD203c and $\mathrm{CD} 11 \mathrm{~b}$ and histamine release by inhibitors of early IgE-mediated signaling. a Syk inhibitor NVP-QAB205. Purified basophils were incubated for $10 \mathrm{~min} \pm \mathrm{NVP}$ QAB205 (or DMSO, vehicle control at a DMSO concentration equivalent to that in the highest NVP-QAB205 concentration drug responses are compared to this response) at the concentrations shown before stimulation with an optimal concentration of anti-IgE antibody $(0.5 \mu \mathrm{g} / \mathrm{ml})$, CD63 (○), CD203c (•), CD11b ( $\square)$ and histamine release $(\boldsymbol{\square})(\mathrm{n}=3)$. b Src-family kinase inhibitor, PP1, reaction conditions and symbols are the same as in $\mathbf{a}(\mathrm{n}=3)$. The average stimulated histamine release in these experiments was $77 \%$.

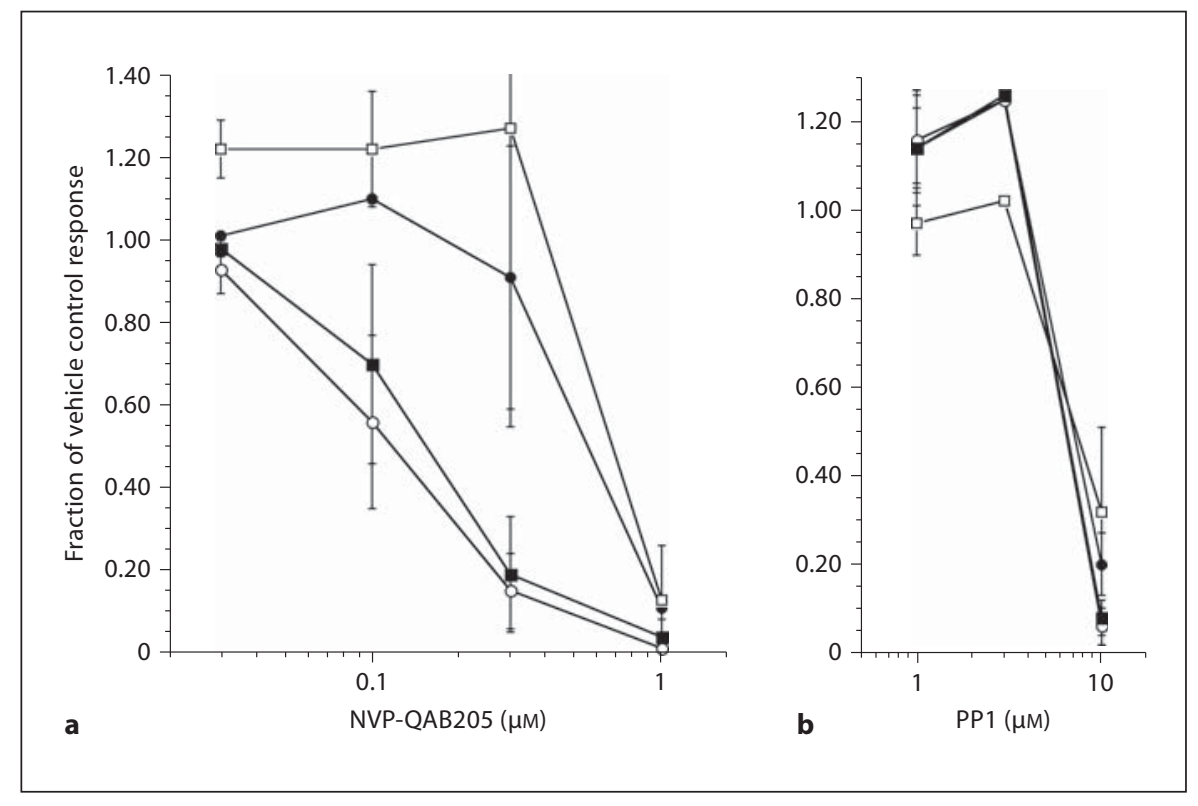

sitization looked very similar to CD203c. To determine if there was dependence of CD203c expression on the earliest elements of IgE-mediated signaling, basophils were stimulated in the presence of a syk inhibitor, NVPQAB205 (a 3rd-generation syk inhibitor that has been extensively studied $[48,49]$ ), effectively inhibiting CD203c, CD11b and CD63 expression (fig. 4a). But once again, there is a subtlety in the results for the syk inhibitor that raises questions about the nature of the signaling requirements for the expression of CD203c and CD11b, both of which are only inhibited at 4 - to 5 -fold higher concentrations of the drug. The earliest step in signaling is the activation of Src-family kinase(s), and the Src-family kinases inhibitor, PP1, inhibited all 4 outcomes at $10 \mu \mathrm{M}$, with a slight enhancement of each outcome at 1-3 $\mu \mathrm{M}$, as demonstrated for histamine release in previous studies [50] (fig. 4b).

There have been mixed indications that expression of CD203c requires extracellular calcium [51]. To test this possibility, basophils were stimulated with fMLP, which generates a robust release of intracellular stores before a significant influx occurs $[52,53]$. The addition of EDTA to the reaction buffer at the same time as the addition of fMLP (in order to prevent leaching of internal stores of calcium prior to the addition of the stimulus) resulted in a $40 \%$ inhibition of CD203c expression (data not shown). If the cells were first loaded with the internal calcium chelator BAPTA (15 $\mu \mathrm{M}$ BAPTA-AM incubated with basophils for $30 \mathrm{~min}$ at $37^{\circ} \mathrm{C}$, followed by washing prior to stimulation $[52,53])$, the simultaneous addition of EDTA (with the fMLP stimulus) resulted in a 100\% inhibition of CD203c expression. Expression of CD63 was more sensitive to EDTA without the BAPTA step, showing $87 \%$ inhibition. It is also known that expression of CD203c is faster than histamine release or CD63 expression, especially during stimulation with phorbol myristate acetate $[4,18]$. In a similar way, CD11b expression occurs rapidly during stimulation with phorbol myristate acetate (data not shown).

\section{Discussion}

This study demonstrated that there was no discordance between inhibition of CD63 expression and histamine release when inhibition was caused by SB203580. A serious challenge to the proposed mechanism of CD63 expression would have been complete inhibition of histamine release without any inhibition of CD63 expression, but even discordance with the partial inhibition of histamine release observed with SB203580 would have raised questions. The expectation is that the more sensitive indicator of inhibition would occur for CD63 expression because, in the proposed model, it is possible to have some histamine release without increased expression of CD63 if the histamine release shifts towards piece-meal degeranulation. Indeed, throughout these studies of inhibition, CD63 tends to be inhibited somewhat more ef- 
fectively than histamine release, suggesting that as stimulation pathways are weakened, piecemeal degranulation may be favored. A similar pattern of behavior was seen in our previously published studies [18] with the unique exception of supraoptimal stimulation which has been shown to generate a stronger early cytosolic calcium response [52]. In other words, scanning through the antiIgE dose-response curve is somewhat unique in that the sub-optimal side of the polyclonal anti-IgE antibody dose-response curve favors piecemeal degranulation, so that there is a qualitative shift in the nature of degranulation as one moves through the dose-response curve to its supraoptimal side.

These experiments also demonstrated a marked discordance in the regulation of CD63 and CD203c expression. It is not entirely clear how SB203580 inhibits secretion because this drug has equal potency for the inhibition of at least 5 kinases: GAK (cyclin-G-associated kinase), RIPK2 (receptor-interacting serine-threonine kinase 2), NLK (nemo-like kinase), CSNK1D (casein kinase 1 delta) and JNK (c-Jun N-terminal kinase), the first 3 of which are likely expressed in basophils based on the presence of a strong mRNA signature (unpublished results), including p38 [54]. But current evidence suggests that all of the known kinases that are inhibited by SB203580, including p38, are considered late-signal transduction elements whose activation occurs downstream of the earliest signaling steps in IgEmediated activation. This later signaling nevertheless alters both histamine release and CD63 expression but appears to have no influence on CD11b and CD203c expression.

We also found that the actin polymerization inhibitors, latrunculin A and cytochalasin D, resulted in concordant enhancement of CD63 expression and histamine release, but once again found discordance in the changes in expression of CD203c and CD11b. Surprisingly, despite the marked effects of these agents on secretion induced by physiological secretagogues and some nonphysiological agents $[34,35]$, there was no effect on CD203c expression; indeed, there was a modest trend towards inhibition. The role of actin polymerization in the maintenance of activation pathways is controversial. There are indications in studies of rodent mast cells that actin polymerization mediates down-regulation of the earliest steps of FceRI-dependent activation $[38,55,56]$; if this were the case, it is reasonable to speculate that all downstream functions would be enhanced. In this context, one would expect that actin-polymerization inhibitors would enhance all indicators of basophil activation, including ac- tivation markers. But actin polymerization inhibitors did not influence CD11b and CD203c expression. This is a surprising result.

To carry this issue one step further: if actin polymerization did have a role in termination mechanisms and we do not observe an effect of actin-polymerization inhibitors, then one might be led to conclude that desensitization might be different for CD11b and CD203c. Desensitization is a general term for the sum of the various processes that serve to terminate an active signal. Some of these processes operate on very early signal transduction steps and would therefore be expected to influence all functions downstream of these early steps. We therefore examined desensitization. Although it appears to occur for the all the measured endpoints, some caution is reserved since for CD11b and CD203c, its rate was somewhat altered (especially at later time points), raising the possibility that the mechanisms for downregulating these 2 responses may still differ, in part, from the mechanisms used to turn off histamine release and, by extension, CD63 expression. Recent studies have also demonstrated the desensitization of CD203c expression, but as noted above, the methodology used a low-dose escalation to establish some degree of desensitization [41]. Taken together, it seems clear that some aspects of desensitization are operating on the expression of CD203c and CD11b. Finally, the observation that actin-polymerization inhibitors did not enhance CD203c or CD11b expression, but that desensitization still occurs, provides further evidence that actin polymerization is not regulating termination mechanisms in human basophils, which supports previous studies that came to this conclusion [35]. These issues aside, the basic result further demonstrates that the signaling pathways for CD11b/CD203c expression differ substantially from the pathways for CD63 expression and histamine release.

The potency of the syk inhibitor, NVP-QAB205, was shifted 4-5 rightward for both CD11b and CD203c expression. This inhibitor is considered a reasonably selective inhibitor of human syk with little inhibition of Srcfamily kinases $[48,57]$, so, while the potency shift could reflect inhibition of other kinases, there is no strong evidence for this explanation. If it were the explanation, it would imply a lack of dependence on syk which would be a surprising conclusion. Alternatively, the strength of the signaling needed for CD203c expression may be smaller than for histamine release, so that more effective inhibition of syk is needed. However, our previous studies on cellular sensitivity do not strictly support this interpreta- 
tion [18]. Without a better model of expression or secretion, it may be difficult to translate the cellular sensitivity studies to this situation. Therefore, it is unclear what the shift in potency implies about the dependence on syk for signaling to CD203c expression, although it does highlight another difference in the signaling requirements for CD203c when compared to CD63. The results with PP1 do suggest that a Src-family kinase is needed for the response, which is not surprising, since, unlike the requirement for syk, no study has dissociated any basophil function from inhibition by PP1.

We have found that CD203c and CD11b appear to follow the same rules of expression. First, they are both rapidly expressed during stimulation with phorbol myristate acetate. Second, they are not inhibited by SB203580. Third, they are not enhanced with actin polymerization inhibitors. In addition, their sensitivity to the syk inhibitor, NVP-QAB205, was shifted 4- to 5-fold. In a previous publication, we also found a 3- to 4 -fold shift in their sensitivity to a Btk inhibitor [58]. There have been many studies of CD11b expression in neutrophils $[23-27,59]$ identifying a vesicular granule that contains $\mathrm{CD} 11 \mathrm{~b}$ that fuses rapidly with the plasma membrane during stimulation. The concordant characteristics and signaling requirements between the expression of $\mathrm{CD} 11 \mathrm{~b}$ and $\mathrm{CD} 203 \mathrm{c}$ suggest that these 2 proteins may be located in the same compartment in human basophils, and the rich literature on the expression of this molecule in neutrophils may also aid the understanding of the signaling requirements for $\mathrm{CD} 203 \mathrm{c}$ expression. This study also demonstrates that the signaling requirements for this alternative intracellular vesicular fusion event are unique from those of normal degranulation. Nevertheless, these are indirect measures of similarity; electron microscopy would be necessary to colocate the 2 proteins in the same compartment.

In summary, several agents known to modify signal transduction in human basophils appear to differentially alter the expression of $\mathrm{CD} 63 /$ histamine release versus CD203c/CD11b expression. This study supports previous indications for different signaling pathways for these 2 classes of outcomes and advocates further caution when interpreting the effects of stimuli on the expression of the various activation markers being used to study human basophils.

\section{Acknowledgements}

This work was supported in part by National Institutes of Health grants AI20253 and AI070345. I would like to thank Valerie Alexander for her technical assistance.

\section{References}

$>1$ de Weck AL, Sanz ML, Gamboa PM, Aberer W, Bienvenu J, Blanca M, Demoly P, Ebo DG, Mayorga L, Monneret G, Sainte-Laudy J: Diagnostic tests based on human basophils: more potentials and perspectives than pitfalls. Int Arch Allergy Immunol 2008;146:177-189.

$\checkmark 2$ Sudheer PS, Hall JE, Read GF, Rowbottom AW, Williams PE: Flow cytometric investigation of peri-anaesthetic anaphylaxis using CD63 and CD203c. Anaesthesia 2005;60: 251-256.

3 Sonneck K, Baumgartner C, Rebuzzi L, Marth K, Chen KW, Hauswirth AW, Florian S, Vrtala S, Buhring HJ, Valenta R, Valent P: Recombinant allergens promote expression of aminopeptidase-n (CD13) on basophils in allergic patients. Int J Immunopathol Pharmacol 2008;21:11-21.

-4 HennersdorfF, Florian S, Jakob A, Baumgartner K, Sonneck K, Nordheim A, Biedermann $\mathrm{T}$, Valent $\mathrm{P}$, Buhring HJ: Identification of CD13, CD107a, and CD164 as novel basophil-activation markers and dissection of two response patterns in time kinetics of IgE-dependent upregulation. Cell Res 2005; 15:325-335
5 Aerts NE, Dombrecht EJ, Bridts CH, Hagendorens MM, de Clerck LS, Stevens WJ, Ebo DG: Simultaneous flow cytometric detection of basophil activation marker CD63 and intracellular phosphorylated p38 mitogen-activated protein kinase in birch pollen allergy. Cytometry B Clin Cytom 2008;76B:8-17.

6 Apostolou E, Deckert K, Puy R, Sandrini A, de Leon MP, Douglass JA, Rolland JM, O’Hehir RE: Anaphylaxis to Gelofusine confirmed by in vitro basophil activation test: a case series. Anaesthesia 2006;61:264-268.

7 Lourenco FD, Azor MH, Santos JC, Prearo E, Maruta CW, Rivitti EA, Duarte AJ, Sato MN: Activated status of basophils in chronic urticaria leads to interleukin-3 hyper-responsiveness and enhancement of histamine release induced by anti-IgE stimulus. Br J Dermatol 2008;158:979-986.

$>8$ Chirumbolo S, Vella A, Ortolani R, De Gironcoli M, Solero P, Tridente G, Bellavite P: Differential response of human basophil activation markers: a multi-parameter flow cytometry approach. Clin Mol Allergy 2008;6:12-25. $\checkmark 9$ Nagao M, Hiraguchi Y, Hosoki K, Tokuda R, Usui T, Masuda S, Yamaguchi M, Fujisawa T: Allergen-induced basophil CD203c expression as a biomarker for rush immunotherapy in patients with Japanese cedar pollinosis. Int Arch Allergy Immunol 2008;146 Suppl 1:47-53.

10 Buhring HJ, Streble A, Valent P: The basophil-specific ectoenzyme E-NPP3 (CD203c) as a marker for cell activation and allergy diagnosis. Int Arch Allergy Immunol 2004; 133:317-329.

11 Boumiza R, Debard AL, Monneret G: The basophil activation test by flow cytometry: recent developments in clinical studies, standardization and emerging perspectives. Clin Mol Allergy 2005;3:9-16.

12 Knol EF, Mul FPJ, Jansen H, Calafat J, Roos D: Monitoring human basophil activation via CD63 monoclonal antibody 435 . J All Clin Immunol 1991;88:328-338.

13 Buhring HJ, Seiffert M, Giesert C, Marxer A, Kanz L, Valent P, Sano K: The basophil activation marker defined by antibody 97A6 is identical to the ectonucleotide pyrophosphatase/phosphodiesterase 3. Blood 2001;97: 3303-3305. 
14 MacGlashan DW Jr: Graded changes in the response of individual human basophils to stimulation: distributional behavior of events temporally coincident with degranulation. J Leukocyte Biology 1995;58:177-188.

-15 Hauswirth AW, Natter S, Ghannadan M, Majlesi Y, Schernthaner GH, Sperr WR, Buhring HJ, Valenta R, Valent P: Recombinant allergens promote expression of CD203c on basophils in sensitized individuals. J Allergy Clin Immunol 2002;110:102109.

16 Gibbs BF, Plath KE, Wolff HH, Grabbe J: Regulation of mediator secretion in human basophils by p38 mitogen-activated protein kinase: phosphorylation is sensitive to the effects of phosphatidylinositol 3-kinase inhibitors and calcium mobilization. J Leukoc Biol 2002;72:391-400.

-17 Monneret G, Boumiza R, Gravel S, Cossette C, Bienvenu J, Rokach J, Powell WS: Effects of prostaglandin $\mathrm{D}(2)$ and 5-lipoxygenase products on the expression of CD203c and CD11b by basophils. J Pharmacol Exp Ther 2005;312:627-634.

- 18 MacGlashan DW Jr: Expression of CD203c and CD63 in human basophils: relationship to differential regulation of piecemeal and anaphylactic degranulation processes. Clin Exp Allergy 2010;40:1365-1377.

19 Dvorak AM: Basophils and mast cells. Piecemeal degranulation in situ and ex vivo: a possible mechanism for cytokine-induced function in disease; in Coffey RG (ed): Granulocyte Responses to Cytokines. New York, Marcel Dekker, 1992, pp 169-271.

-20 Dvorak AM, Warner JA, Kissell S, Lichtenstein LM, MacGlashan DW Jr: F-met peptide-induced degranulation of human basophils. Lab Invest 1991;64:234-253.

-21 Dvorak AM, MacGlashan DW Jr, Morgan ES, Lichtenstein LM: Vesicular transport of histamine in stimulated human basophils. Blood 1996;88:4090-4101.

-22 Ebo DG, Dombrecht EJ, Bridts CH, Aerts NE, de Clerck LS, Stevens WJ: Combined analysis of intracellular signalling and immunophenotype of human peripheral blood basophils by flow cytometry: a proof of concept. Clin Exp Allergy 2007;37:1668-1675.

-23 Bainton DF, Miller LJ, Kishimoto TK, Springer TA: Leukocyte adhesion receptors are stored in peroxidase-negative granules of human neutrophils. J Exp Med 1987;166: 1641-1653.

-24 Miller LJ, Bainton DF, Borregaard N, Springer TA: Stimulated mobilization of monocyte Mac-1 and p150,95 adhesion proteins from an intracellular vesicular compartment to the cell surface. J Clin Invest 1987;80:535544 .
25 Borregaard N, Kjeldsen L, Sengelov H, Diamond MS, Springer TA, Anderson HC, Kishimoto TK, Bainton DF: Changes in subcellular localization and surface expression of L-selectin, alkaline phosphatase, and Mac-1 in human neutrophils during stimulation with inflammatory mediators. J Leukoc Biol 1994;56:80-87.

26 Hughes BJ, Hollers JC, Crockett-Torabi E, Smith CW: Recruitment of CD11b/CD18 to the neutrophil surface and adherence-dependent cell locomotion. J Clin Invest 1992; 90:1687-1696.

27 Monk PN, Banks P: The role of protein kinase $\mathrm{C}$ activation and inositol phosphate production in the regulation of cell-surface expression of Mac-1 by complement fragment C5a. Biochim Biophys Acta 1991;1092: 251-255.

28 Bochner BS, Sterbinsky SA: Altered expression of CD11 and Leu-8 during human basophil degranulation. J Immunol 1991;146: 2367-2373.

29 Urata C, Siraganian RP: Pharmacologic modulation of the $\mathrm{IgE}$ or $\mathrm{Ca}^{+}$ionophore A23187 mediated $\mathrm{Ca}^{+}$influx, phospholipase activation, and histamine release in rat basophilic leukemia cells. Int Arch Allergy Appl Immunol 1985;78:92-100.

30 Seagrave J, Oliver JM: Antigen-dependent transition of $\operatorname{IgE}$ to a detergent-insoluble form is associated with reduced IgE receptor-dependent secretion from RBL-2H3 mast cells. J Cell Physiol 1990;144:128-136.

31 Narasimhan V, Holowka D, Baird B: Microfilaments regulate the rate of exocytosis in rat basophilic leukemia cells. Biochem Biophys Res Commun 1990;171:222-229.

32 Gillespie E, Lichtenstein LM: Histamine from human leukocytes: studies with deuterium oxide, colchicine and cytochalasin B. J Clin Invest 1972;51:2941-2947.

33 Pfeiffer JR, Seagrave JC, Davis BH, Deanin GG, Oliver JM: Membrane and cytoskeletal changes associated with IgE-mediated serotonin release from rat basophilic leukemia cells. J Cell Biol 1985;101:2145-2155.

34 Vilarino N, MacGlashan DW Jr: Actin cytoskeleton-dependent down-regulation of early IgE-mediated signaling in human basophils. J Leukoc Biol 2004;75:928-937.

35 MacGlashan D Jr, Vilarino N: Polymerization of actin does not regulate desensitization in human basophils. J Leukoc Biol 2009; 85:627-637.

36 MacGlashan DW Jr, White JM, Huang SK, Ono SJ, Schroeder J, Lichtenstein LM: Secretion of interleukin- 4 from human basophils: the relationship between IL-4 mRNA and protein in resting and stimulated basophils. J Immunol 1994;152:3006-3016.

-37 Siraganian RP: An automated continuousflow system for the extraction and fluorometric analysis of histamine. Anal Biochem 1974;57:383-394.
38 Pierini L, Harris NT, Holowka D, Baird B: Evidence supporting a role for microfilaments in regulating the coupling between poorly dissociable IgE-Fc epsilonRI aggregates downstream signaling pathways. Biochemistry 1997;36:7447-7456.

39 Holowka D, Sheets ED, Baird B: Interactions between $\mathrm{Fc}$ (epsilon)RI and lipid raft components are regulated by the actin cytoskeleton. J Cell Sci 2000;113:1009-1019.

40 Frigeri L, Apgar JR: The role of actin microfilaments in the down-regulation of the degranulation response in RBL-2H3 mast cells. J Immunol 1999;162:2243-2250.

41 Lund G, Jacobi H, Skov PS, Holm J, Lund K: Effect on cell surface markers following allergen-induced desensitization of human whole-blood basophils. Int Arch Allergy Immunol 2010;153:323-334.

42 Lichtenstein LM, De Bernardo R: IgE mediated histamine release: in vitro separation into two phases. Int Arch Allergy Appl Immunol 1971;41:56-71.

43 Mendoza GR, Minagawa K: Subthreshold and suboptimal desensitization human basophils. I. Kinetics of decay of releasability. Int Arch Allergy Appl Immunol 1982;68: 101-107.

44 MacGlashan DW Jr, Mogowski M, Lichtenstein LM: Studies of antigen binding on human basophils. II. Continued expression of antigen-specific IgE during antigen-induced desensitization. J Immunol 1983;130:23372342.

45 MacGlashan DW Jr: Two regions of downregulation in the IgE-mediated signaling pathway in human basophils. J Immunol 2003;170:4814-4925.

46 MacGlashan DW Jr: Self-termination/anergic mechanisms in human basophils and mast Cells. Int Arch Allergy Immunol 2009; 150:109-121

47 MacGlashan DW Jr, Laven-Phillips S, Miura $\mathrm{K}$ : IgE-mediated desensitization in human basophils and mast cells: Front Biosci 1998; 3:d746-d756.

48 MacGlashan DW Jr, Vilarino N: Nonspecific desensitization, functional memory and the characteristics of SHIP phosphorylation following IgE-mediated stimulation of human basophils. J Immunol 2006;177:1040-1051.

49 MacGlashan DW Jr, Undem BJ: Inducing an anergic state in mast cells and basophils without secretion. J Allergy Clin Immunol 2008;121:1500-1506.

50 Lavens-Phillips SE, Miura K, MacGlashan DW Jr: Pharmacology of IgE-mediated desensitization of human basophils: effects of protein kinase $\mathrm{C}$ and Src-family kinase inhibitors. Biochem Pharmacol 2000;60:17171727. 
-51 Gernez Y, Tirouvanziam R, Yu G, Ghosn EE, Reshamwala N, Nguyen T, Tsai M, Galli SJ, Herzenberg LA, Nadeau KC: Basophil CD203c levels are increased at baseline and can be used to monitor omalizumab treatment in subjects with nut allergy. Int Arch Allergy Immunol 2010;154:318-327.

-52 MacGlashan DW Jr, Botana L: Biphasic Ca ${ }^{++}$ responses in human basophils: evidence that the initial transient elevation associated with mobilization of intracellular calcium is an insufficient signal for degranulation. J Immunol 1993;150:980-991.

53 MacGlashan DW Jr, Hubbard WC: Interleukin-3 alters free arachidonic acid generation in C5a-stimulated human basophils. J Immunol 1993;151:6358-6369.
54 Karaman MW, Herrgard S, Treiber DK, Gallant P, Atteridge CE, Campbell BT, Chan KW, Ciceri P, Davis MI, Edeen PT, Faraoni R, Floyd M, Hunt JP, Lockhart DJ, Milanov ZV, Morrison MJ, Pallares G, Patel HK, Pritchard S, Wodicka LM, Zarrinkar PP: A quantitative analysis of kinase inhibitor selectivity. Nat Biotechnol 2008;26:127-132.

55 Field KA, Holowka D, Baird B: Compartmentalized activation of the high affinity immunoglobulin E receptor within membrane domains. J Biol Chem 1997;272:42764280.

56 Holowka D, Gosse JA, Hammond AT, Han X, Sengupta P, Smith NL, Wagenknecht-Wiesner A, Wu M, Young RM, Baird B: Lipid segregation and IgE receptor signaling: a decade of progress. Biochim Biophys Acta 2005;1746:252-259.
57 Collingwood SP, Hayler J, Le Grand DM, Mattes H, Menear KA, Walker CV, Cockcroft X: Preparation of anilinopurine derivatives as inhibitors of tyrosine protein kinase syk: PCT Int Appl. Canada, Novartis, 2001, WO01/09134,

58 Macglashan DW Jr, Honigberg L, Smith A, Buggy J, Schroeder JT: Inhibition of IgE-mediated secretion from human basophils with a highly selective Bruton's tyrosine kinase, Btk inhibitor. Int Immunopharmacol 2011; 11:475-479.

59 Monk PN, Barker MD, Partridge LJ: Multiple signalling pathways in the C5a-induced expression of adhesion receptor Mac-1. Biochim Biophys Acta 1994;1221:323-329. 